\title{
Predisposing factors analysis of mandibular anterior tooth crowding in the mixed dentition period by the tooth size and dental arch width
}

\author{
Ratna Indriyanti*, Sjarief Hidajat Efendi**, Ani Melani Maskoen*** Eriska Riyanti** \\ *Medical Sciences Doctoral Program, Faculty of Medicine, Universitas Padjadjaran, Indonesia \\ **Department of Pedodontics, Faculty of Dentistry, Universitas Padjadjaran, Indonesia \\ ***Department of Oral Biology, Faculty of Dentistry, Universitas Padjadjaran, Indonesia
}

\begin{abstract}
Introduction: Tooth crowding can cause complaints if not treated early - this condition resulting in aesthetic disorders, and also masticatory and speech function disruption. The study was aimed to determine the predisposing factors of tooth crowding in the mixed dentition period by the tooth size and dental arch width. Methods: Research type was random cross-sectional. The sample was as much as 29 children with mandibular casting; then the mandibular model cast of these 6 -9-years old children were divided into two groups according to the crowding condition in the mandibular anterior region, and the measurement was performed afterwards. Space available category was (A/A1), mesiodistal width of mandibular incisor (B/B1), total arch length (C/C1), intercanine width (D/D1), first primary intermolar width (E/E1), second primary intermolar width (F/F1), first permanent intermolar width $(\mathrm{G} / \mathrm{G} 1)$, interalveolar width $(\mathrm{H} / \mathrm{H} 1)$. Result: The results of the t-test showed significant differences $(\mathrm{p}$ $<0.05$ ) in the available space for 4 incisors, where the space was larger in the non-crowded group with a difference of $2.22 \mathrm{~mm}$ and the mesiodistal sizes of these 4 incisors was larger in the crowded teeth group, with the difference of $1.8 \mathrm{~mm}$. The results of the Pearson correlation coefficient showed a positive relationship to several measurements, namely $\mathrm{D}$ to $\mathrm{C} 1, \mathrm{E}$ to $\mathrm{D} 1$ and $\mathrm{H}$ to $\mathrm{B} 1, \mathrm{C} 1, \mathrm{D} 1, \mathrm{~F} 1$ and $\mathrm{G} 1$, with the $\mathrm{t}$-value $>3$ and the $\mathrm{r}$-value was closer to 1 , which showed a correlation with strong closeness degree $(r$ $>0.61$ ). Conclusion: Predisposing factors of tooth crowding in the mixed dentition period were the first intercanine width $(D)$, first primary intermolar width $(E)$, and alveolar arch width $(H)$.
\end{abstract}

Keywords: Tooth crowding, arch dimension, mixed dentition period

P-ISSN 1979-0201, e-ISSN 2549-6212 Available from:http://jurnal.unpad.ac.id/pjd/article/view/18375

DOI:10.24198/pjd.vol30no3.18375

Submission: Aug 14, 2018; Accepted: Oct 09, 2018; Publishing online: Nov 30, 2018

Corresponding author: Ratna Indriyanti, Medical Sciences Doctoral Program, Faculty of Medicine, Univ Padjadjaran Jalan Professor Eyckman 38, Bandung 40161, Indonesia. Phone: +6287821111032; Email: indriluvsiens@gmail.com 


\section{INTRODUCTION}

Human needs for a good quality of life are the basic natural needs of every human being. Along with the development of science and the increase in socio-economic life, the demand to fulfil physical beauty including the face becomes very important. Crowded teeth can occur from childhood, and usually occur in permanent teeth and rarely occur in primary teeth. ${ }^{1}$ Parental concerns are typically directed at the severity of crowded teeth until adulthood which will affect facial aesthetics ${ }^{2,3}$, however, crowded teeth can develop into a bigger problem for sufferers, because the teeth will be difficult to clean. When cleaning teeth or brushing teeth, toothbrushes are difficult to reach the rest of the food that sticks to the interdental area of the crowded teeth so that plaque accumulation and calculus form then triggers cavities (caries) and gum disease (gingivitis) and even damage to the supporting tissues of the teeth (periodontitis) so that teeth become rocky and eventually have to be removed. ${ }^{4}$ Research conducted in Poland in 2010 showed that the prevalence of caries and DMF-T in anterior teeth with crowded teeth was higher than in non-crowded teeth. ${ }^{5}$

The highest prevalence of crowded teeth is in the anterior region and involves the same tooth on each side, for example, right lateral incisor and left lateral incisor. Crowded teeth in the premolar and molar regions are usually associated with adjacent teeth, for example, the first right premolar and the second right premolar. Three patterns of crowded teeth are found in the anterior region, namely symmetrical patterns, irregular patterns and irregular patterns. The first pattern is related to the discrepancy factor, while the last two patterns are related to factors such as occlusal force and centre of gravity. ${ }^{6}$

Other studies have focused on the effects of soft tissue pressure; it was reported that the volume and position of the tongue are related to crowded teeth, while it was also reported that tooth inclination is affected by cheek pressure. Other research reports show a relationship between crowded teeth and morphological characteristics of the mandible. A longitudinal study showed eruption of the first molar towards the anterior effect on delayed mandibular teeth. Also, the occlusal power components in the anterior and anterior occlusion patterns such as overjet or overbite are also known to be associated with teeth. ${ }^{6}$

Several studies have shown that crowded teeth as a form of malocclusion can occur due to dentofacial imbalances. Factors that influence malocclusion are divided into prenatal and postnatal factors. Prenatal factors consist of genetic, differentiation and congenital. While postnatal factors consist of development, functional and environmental. ${ }^{7,8}$ Although the role of environment and genetics in the aetiology of crowded teeth is still questionable; new evidence shows that crowded teeth are malocclusions that commonly occur for human populations in the modern industrial era, which occur as a result of current food processing methods. ${ }^{9}$

Malocclusion prevalence in 2008 reached $80 \%$ and ranked third after caries and periodontal disease. ${ }^{10}$ Types of malocclusion that can be found include protrusion, intrusion and extrusion, crossbite, open bite, crowding, and diastema. Crowded teeth are the highest component of the prevalence of malocclusion in dental patients. It can be seen from research in the Department of Orthodontics of Faculty of Dentistry University of Indonesia in 1999 which reported that 270 samples in children aged $12-14$ years were found to have $44.9 \%$ crowded teeth. ${ }^{11}$

Growth and development of the maxilla and mandible are determined by genetics and environmental factors. ${ }^{1}$ Identification of these factors and their mechanisms will help diagnosis, prediction, and treatment for bone variations. Mandibular growth is highly dependent on cartilage growth and interactions between various factors such as genetic disposition, nutrition, homeostasis, hormones and growth factors.

Some authors stated that there was a correlation between the dimensions of the jaw arch length and crowded teeth, then there were also results of research stated that individual dental arches without crowded teeth have a size of about $4 \mathrm{~mm}$ wider than the arch with crowded teeth. Also, there is a large width of the lower jaw in the anterior and posterior sections of children whose permanent teeth are not crowded. Other researchers mentioned a more significant correlation between dental arch size and crowded teeth compared to the size of the teeth and teeth 
crowded. The results of the evaluation of another study on crowded teeth in permanent teeth obtained significant differences in the curvature between the group of crowded teeth and noncrowded teeth. $^{1}$

Controversies regarding the relationship between crowded teeth and the size of the jaw and mesiodistal size of the teeth, and other causes of crowding, namely genetic and environmental factors, have a great desire to trace the underlying factors that may contribute to the occurrence of crowding in the mandible of children in the early period of mixed dentistry. This study was aimed to determine the predisposing factors of tooth crowding in the mixed dentition period by the tooth size and dental arch width.

\section{METHODS}

Child patients aged 6 to 9 years who came to the Dental Hospital of Universitas Padjadjaran, who were by the inclusion criteria, being printed on their mandible. The research subjects were selected from the age of 6 to 9 years, because at this age included in the age group of mixed teeth, where the incisors and the first molar remained erupted perfectly whereas the first canines and first and second molars were in place.

The selection of research subjects with skeletal class 1 inclusion criteria and good tooth dimensions was expected not to affect the dimensions of the arch of the jaw. The inclusion criteria for this study were class 1 skeletal patterns. The initial stages of the mixed dentition period were: four permanent mandibular incisors, firstborn canines, first molars and molar remained erupted. These patients also have never received orthodontic treatment. The exclusion criteria are the loss of incisors and permanent congenital molar and early loss of teeth. The loss of tooth dimensions due to enamel caries that have not yet reached dentin and the presence of attrition will be included in this criterion. Exclusion criteria are congenital permanent incisor and permanent tooth loss and early tooth loss.

The sample was cast from the mandibular teeth, and the teeth model was made from the mould. In the dental model, the dental mesiodistal and the curvature of the lingual region of the mandible were measured. All measurements were made on the model using a calliper with an accuracy of $0.01 \mathrm{~mm}$. All measurements were repeated two weeks later to anticipate any measurement errors.

They are referring to the incisor liability index. Namely, the term tooth irregularity/ definition was defined as the adequacy of the space available to accommodate four permanent incisors. Crowded teeth were defined as the difference between the amount of room size from the left first mesial canine to the available space and the number of permanent mandibular incisors.

The average difference between the number of four mandibular incisors and the available space was $1.6 \mathrm{~mm}$, so this condition is called mild/normal congestion. For this reason, if the index of the mandibular anterior teeth was $\leq 1.6$ $\mathrm{mm}$, it was included in the criteria of normal or not congested. Meanwhile, subjects with crowded tooth index $\geq 1.6 \mathrm{~mm}$ were included in the criteria for crowded teeth. The study by Howe et al. ${ }^{12}$ and Radnzic ${ }^{1,13}$, reported that the size of the jaw width in the non-crowded group was larger than that of the crowded tooth group.

The models that obtained were then divided into two groups based on the presence or absence of anterior mandibular crowding. The crowding value of $\leq 1.6 \mathrm{~mm}$ was grouped in the Normal / NonCrowded / (NCT) group, while the value of $\geq 1.6$ $\mathrm{mm}$ was grouped in the Crowded Tooth group (CT).

Measuring the jaw arch width was performed by determining the size of the jaw which were: 1 ) The available space was: the measurement results starting from the contact points of the mesial part of the first canine to the fixed contact points of the seventh and eighth regions, then summed with the measurements from the central incisive contact points of the seventh and eighth regions to the point of contact of the firstborn canine (Figure 1). Incisor width was: the width of each incisor is measured and added to produce a total incisor width (Figure 1b and 1c). Crowded teeth was the width of the incisors deducted from the incisor space available to calculate the severity of the crowded teeth.

The total jaw arch length was: the total length of the mandibular arch was measured from the mesial part of the first permanent molar on the right side to the mesial part of the first left permanent molar, as defined by 
Warren and Bishara. ${ }^{14}$ For the anterior segment, measurements were made from the contact point from permanent incisors at the point of contact between the firstborn canine and the first molar. For the posterior segment, measurements were made from the contact point between the first canine and the first molar to the distal point of the second primary molar.

The two long segments for the right and left sides were then summed to determine the total curved length (Figure 1); Figure 2 describes the arch width definition such as follow: (1) showed the inter width which was the distance between the tip of the cusp of the mandibular first canine teeth; (2) showed the molar I width which was the distance between the mesiolingual tips of the mandibular peak of the first primary molar; (3) showed the molar II width which was the distance between the mesiobuccal tips peak of the second primary molar; (4) showed the permanent molar width which was the distance between tips of mandibular mesiobuccal peaks of permanent first molar; and (5) showed the interalveolar width which was the distance between the mucogingival boundary below the buccal groove of the right and left mandibular permanent first molar.

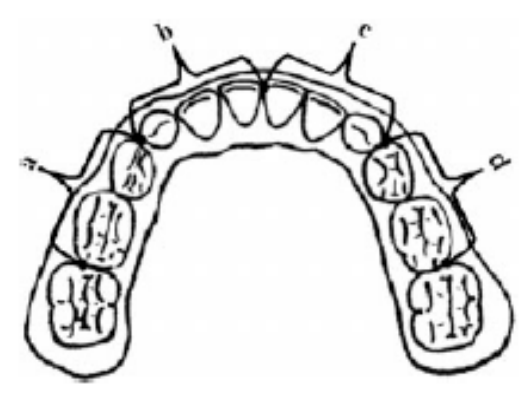

Figure 1. Arch length; $a+b+c+d$

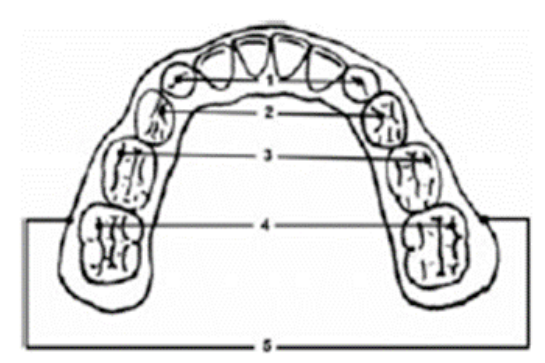

Figure 2. (1) Width between primary canines (2) Width between the first primary molars (3) Width between firstborn second molars (4) The width between the first permanent molars (5) Interalveolar width
Statistical comparisons of the two groups were carried out by independent sample t-test. Pearson Correlation was calculated to measure the reciprocal relationship between crowded teeth and all other measurements, namely the inter canine width, width between first primary molar, width between second primary molar, width between first permanent molars, and interalveolar width.

\section{RESULT}

Comparisons between the Non-Crowded Teeth (NCT) group and Crowded Teeth (CT) group can be seen in Table 1. All measurements showed no significant differences between the NCT and $\mathrm{CT}$ groups, except for the available room measurements in four permanent mandibular incisors and the number of mesiodistal width of permanent mandibular incisors (A and $A 1)$ with the difference of $2.22 \mathrm{~mm}(p=0.00 ; p<0.05)$, while for B and B1 was $1.80 \mathrm{~mm}(p=0.007 ; p<$ 0.05).

The results of difference test between $\mathrm{CT}$ and NCT groups using the t-test can be seen in Table 1 . The results above show that there were significant differences between the available space for four anterior mandibular incisors with the $p$-value of 0.003 and the mesiodistal size of four mandibular incisors between CT and NCT groups with the $p$-value of 0.007 . Both $p$-values were $<0.05$.

The available space for four incisors was larger in the NCT group (2.22 mm difference), while the number of mesiodistal size of four incisors was larger in the CT group (1.8 $\mathrm{mm}$ difference).

Table 2 presents the results of the correlation analysis of each measurement using the Pearson correlation coefficient test. Correlation between the length of the jaw arch (C1) in the group of noncrowded teeth with the width of primary canines $(D, r=0.841 ; t=4.1126)$, then between the available space in the group of non-crowded teeth (A1) to the first intercanine width (D, $r=0.762$; $t=3.132224)$, as well as the primary intercanine width of the non-crowded tooth group (D1) with the width between primary first molar $(E)$ with a value of $r=0.841$ and $t=4.1126$. There was also a significant correlation between the number 
Table 1. T-test results of the parameter measurement: the mesiodistal width and width of the available jaw space between NCT and CT groups

\begin{tabular}{|c|c|c|c|c|c|c|c|}
\hline \multirow{3}{*}{$\begin{array}{l}\text { Variable }(\mathrm{mm}) \\
\text { Available space }\end{array}$} & \multirow{2}{*}{\multicolumn{2}{|c|}{$\begin{array}{c}\text { Crowded teeth group } \\
(\mathrm{n}=9)\end{array}$}} & \multirow{2}{*}{\multicolumn{2}{|c|}{$\begin{array}{c}\text { Non-crowded teeth group } \\
(\mathrm{n}=20)\end{array}$}} & \multirow{2}{*}{\multicolumn{2}{|c|}{ Difference (Cl 95\%) }} & \multirow{3}{*}{$\frac{P}{0.003^{*}}$} \\
\hline & & & & & & & \\
\hline & $A$ & $20.96(1.70)$ & $\mathrm{A} 1$ & $22.71(2.30)$ & 2.22 & $(0.93 ; 3.50)$ & \\
\hline Total incisor width & B & $24.08(2.06)$ & B1 & $22.28(1.25)$ & 1.80 & $(0.54 ; 3.07)$ & $0.007^{\#}$ \\
\hline Total arch length & C & $68.64(3.47)$ & C1 & $69.91(3.37)$ & -1.27 & $(-4.07 ; 1.53)$ & $0.362^{* *}$ \\
\hline Intercanine width & D & $25.85(2.07)$ & D1 & $26.53(2.31)$ & -0.68 & $(-2.53 ; 1.17)$ & $0.456^{* *}$ \\
\hline Intermolar width I & $\mathrm{E}$ & $28.07(2.55)$ & E1 & $28.41(2.01)$ & -0.34 & $(-2.14 ; 1.46)$ & $0.705^{* *}$ \\
\hline Intermolar width II & $\mathrm{F}$ & $37.80(1.68)$ & F1 & $39.01(1.94)$ & -1.21 & $(-2.74 ; 0.32)$ & $0.118^{* *}$ \\
\hline Permanent intermolar width & G & $46.66(3.53)$ & G1 & $47.12(3.69)$ & 0.97 & $(-1.15 ; 2.96)$ & $0.370^{* *}$ \\
\hline Interalveolar width & $\mathrm{H}$ & $59.25(2.21)$ & $\mathrm{H} 1$ & $58.87(2.15)$ & 0.38 & $(-1.41 ; 2.16)$ & $0.667^{* *}$ \\
\hline
\end{tabular}

${ }^{*} \mathrm{P}<0.05$ significant; ${ }^{* *} \mathrm{P}>0.05$ not significant

Table 2. The results of Pearson correlation and T-test of the parameters of the mesiodistal width and width of the available jaw space between the NCT and CT group

\begin{tabular}{|c|c|c|c|c|c|c|c|c|}
\hline \multirow{2}{*}{\multicolumn{2}{|c|}{$\begin{array}{l}\text { Correlation } \\
\text { coefficient }\end{array}$}} & \multicolumn{7}{|c|}{ Non-Crowded Teeth Group } \\
\hline & & \multirow{2}{*}{$\begin{array}{c}\mathrm{A} 1 \\
0.508\end{array}$} & \multirow[t]{2}{*}{ B1 } & \multirow[t]{2}{*}{ C1 } & \multirow[t]{2}{*}{ D1 } & \multirow[t]{2}{*}{$\mathrm{E} 1$} & \multirow[t]{2}{*}{ F1 } & \multirow[t]{2}{*}{ G1 } \\
\hline$B$ & 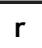 & & & & & & & \\
\hline & $\mathrm{t}$ & 1.560377 & & & & & & \\
\hline \multirow[t]{2}{*}{ C } & $\mathbf{r}$ & 0.585 & 0.536 & & & & & \\
\hline & $\mathrm{t}$ & 1.908386 & 1.679806 & & & & & \\
\hline \multirow[t]{2}{*}{ D } & $r$ & $0.762^{*}$ & 0.569 & $0.841^{*}$ & & & & \\
\hline & $\mathrm{t}$ & $3.11324^{* *}$ & 1.830675 & $4.112629^{* *}$ & & & & \\
\hline \multirow[t]{2}{*}{$\mathrm{E}$} & $r$ & 0.732 & 0.41 & 0.418 & $0.841^{*}$ & & & \\
\hline & $\mathrm{t}$ & 2.84262 & 1.189316 & 1.217379 & $4.112629^{* *}$ & & & \\
\hline \multirow[t]{2}{*}{$\mathrm{F}$} & $r$ & 0.411 & 0.721 & 0.593 & 0.666 & 0.534 & & \\
\hline & $\mathrm{t}$ & 1.192806 & 2.752908 & 1.948492 & 2.362177 & 1.671032 & & \\
\hline \multirow[t]{2}{*}{ G } & $r$ & 0.187 & 0.68 & 0.586 & 0.575 & 0.025 & 0.73 & \\
\hline & $\mathrm{t}$ & 0.50364 & 2.453739 & 1.913352 & 1.85944 & 0.066164 & 2.825966 & \\
\hline \multirow[t]{2}{*}{$\mathrm{H}$} & $r$ & 0.663 & $0.805^{*}$ & $0.818^{*}$ & $0.866^{*}$ & 0.499 & $0.835^{*}$ & $0.817^{*}$ \\
\hline & $\mathrm{t}$ & 2.343157 & $3.589955^{* *}$ & $3.762441^{* *}$ & $4.582038^{* *}$ & 1.523456 & $4.014907^{* *}$ & $3.748591^{* *}$ \\
\hline
\end{tabular}

${ }^{*} \mathrm{r}$ approaches the value of $1 ;{ }^{* *} \mathrm{t}>3$

of mesiodistal sizes of four mandibular anterior teeth (B1; $r=0.805 ; t=3.5899)$, the length of the jaw arch $(\mathrm{C} 1 ; \mathrm{r}=0.818 ; \mathrm{t}=3.7624)$, width between $\mathrm{F} 1$ first molars; $(r=0.835 ; \mathrm{t}=4.0149)$ and the width between the permanent first molars $(\mathrm{G} 1 ; \mathrm{r}=0.817 ; \mathrm{t}=3.7485)$ with respect to the alveolar arch width $(\mathrm{H})$.

\section{DISCUSSION}

The results of the correlation analysis between the crowded teeth and non-crowded teeth (t-test) in Table 1 , showed a significant difference $(p<$ 0.05 ) between available space and the number of mesiodistal sizes of four permanent mandibular incisors (total incisors width). While the results of the analysis of other parameter measurements did not show a significant difference. The results of this study are in accordance with previous studies by Singh and Shivaprakash ${ }^{6}$, namely, there were significant differences in the size of the mandibular length in mild and severe crowded teeth, where severely crowded teeth had a shorter length of mandible compared to mandibular length in mild crowded teeth. Likewise, there was a significant relationship between crowded teeth with mandibular length. Based on the results of this study, it was also seen that the mesiodistal 
number of four larger mandibular incisors in the crowded tooth group, according to previous studies by Poosti and Jalali. ${ }^{15}$

Table 1 shows that available space in the crowded teeth group appears smaller than in the non-crowded group. Whereas the mesiodistal size of the four jaw fixed incisors appears larger in the crowded teeth group compared to the noncrowded teeth group. Research from Janson et al., Carty et al., and Mills et al. ${ }^{1,16,17}$ reported a significant association between crowded teeth and jaw arch size, whereas according to Grover et al. and Mc Keown et al. ${ }^{18,19}$ the association of dental arches with the occurrence of crowded teeth is stronger than the size of the mesiodistal teeth for the occurrence of crowded teeth. Sardarian et al. and Norderval et al. ${ }^{20,21}$ reported that the mesiodistal size of the four mandibular incisors was significantly larger in the crowded teeth group. Factors related to the occurrence of crowded teeth in the mandibular incisors are the dimensions of the jaw arch of the intercanine size and the mandibular growth pattern, environment, will affect the intercanine distance. ${ }^{6}$

The results of the study on dental models of Swedish children aged 7, 9, 10, 13 years were longitudinal, showing intercanine sizes of less than $26 \mathrm{~mm}$ occurring in crowded teeth. Whereas if the size of the intercanine were more than $28 \mathrm{~mm}$, it would not be at risk for the occurrence of crowded teeth. Hagberg ${ }^{22}$ also reported that the size of mandibular first intercanine, mandibular first and second intermolar and the significantly lower mandibular interalveolar distance in non-crowded teeth group. According to Ghaderi ${ }^{23}$, when the permanent mandibular incision erupts, it will be followed by an enlargement of the intercanine of 2-3 $\mathrm{mm}$. So based on this study, if the direction of the eruption of mandibular incisor was not following the correct direction of eruption, due to genetic and environmental factors, it would affect the intercanine distance.

The results of the correlation analysis between various measurements (Pearson analysis) presented in Table 2 show a strong correlation between the first intercanine distance (D) and jaw arch length (C1). This result indicates that the higher the $D$ value will increase the value of $C 1$. Similarly, the size of the primary first intermolar distance $(E)$ is closely related to the first intercanine distance in non-crowded teeth (D1). So that the higher the primary first intermolar distance $(E)$, the higher the first intercanine distance (D1). The results of other measurement analyzes are clear that the interalveolar $(\mathrm{H})$ width of the crowded tooth group was strongly correlated with the mesiodistal size of the four permanent mandibular incisors (B1), the total number of mandibular arch (C1), the width of the mandibular first intercanine (D1), the first mandibular intermolar width (E1), and the permanent first mandibular intermolar width (G1). The above description shows that the higher the size of the mandibular interalveolar, the higher the size of $B, C, D, F, G$ in the noncrowded teeth group, and vice versa, so that the occurrence of more substantial crowding occurs due to variations in the size of the mandibular interalveolar. Based on the results of previous studies, it was explained that the classification of the dimensions of the jaw arch was determined by the supporting bone configuration and followed by tooth eruption, and was also influenced by the muscles around the oral cavity and the force produced by the functional activities of the oral cavity. Any disturbance in supporting bone growth or tooth eruption will result in abnormal conditions. The growth and development of the mandible in various directions allows the tooth eruption to proceed as it should so that the crowded tooth condition can be prevented. ${ }^{24}$

The results of the average measurements of tooth size measurements did show significant results, but when viewed from the results of correlation analysis showed a significant direct correlation between crowded teeth with interalveolar distance $(H)$. The results of this analysis indicated that the dimensions of the jaw play an important role compared to the size of teeth in the occurrence of crowded teeth. Analysis of predisposing factors of mandibular anterior tooth crowding in the mixed dentition period is very important for future care and prevention planning.

\section{CONCLUSION}

Predisposing factors of tooth crowding in the mixed dentition period were the first intercanine width (D), first primary intermolar width (E), and alveolar arch width $(H)$. 


\section{REFERENCES}

1. Janson G, Goizueta OE, Garib DG, Janson M. Relationship between maxillary and mandibular base lengths and dental crowding in patients with complete class II malocclusions. Angle Orthod. 2011;81(2):21721. DOI: $10.2319 / 062110-338.1$.

2. Melo L, Ono Y, Takagi Y. Indicators of mandibular dental crowding in the mixed dentition. Pediatr Dent. 2001;23(2):118-22.

3. Jonsson T, Magnusson TE. Crowding and spacing in the dental arches: Long-term development in treated and untreated subjects. Am J Orthod Dentofacial Orthop. 2010;138(4):384.e1-384. e7. DOI: 10.1016/j.ajodo.2010.03.024.

4. Sasea A, Lampus BS, Supit A. Gambaran status kebersihan rongga mulut dan status gingiva pada mahasiswa dengan gigi berjejal. J e-GiGi. 2013;1(1):52-8.

5. Buczkowska-Radlinska J, Szyszka-Sommerfeld L, Wozniak K. Anterior tooth crowding and prevalence of dental caries in Szczecin, Poland. Community Dent Health. 2012;29(2):168-72.

6. Singh S, Shivaprakash G. To Evaluate the Correlation Between Skeletal and Dental Parameters to the Amount of Crowding in Class II Div. 1 Malocclusions. J Clin Diagn Res. 2017;11(9):ZC22-ZC27. DOI: 10.7860/ JCDR/2017/27675.10566.

7. Andreasen JO, Andreasen FM, Andersson L. Textbook and color atlas of traumatic injuries to the teeth. $4^{\text {th }}$ ed. Copenhagen: Blackwell Munksgaard; 2007.

8. Alam MK. 2012. A to Z Orthodontics, Vol 13, Fixed Appliances. PPSP Publication: Penang; 2012. p. 3-28.

9. Proffit WR, Fields HW Jr., Sarver DM. Contemporary Orthodontics. $6^{\text {th }}$ ed. London: Elsevier Health Science; 2007. p. 27-30.

10. Normando D, Almeida MA, Quintao CC. Dental crowding: the role of genetics and tooth wear. Angle Orthod. 2013;83(1):10-5. DOI: 10.2319/020112-91.1.

11. Susanto $C$. Need dan demand serta akibat dari maloklusipadasiswaSMUNegerilBinjai [thesis]. Medan: University of North Sumatra; 2010.

12. Malohing D, Anindita PS, Gunawan P. Status karies pada gigi berjejal di SD Negeri 12 Tuminting. J e-GiGi. 2013;1(2):94-8.

13. Barros SE, Chiqueto K, Janson G. Impact of dentofacial development on early mandibular incisor crowding. Am J Orthod Dentofacial Orthop. 2016;150(2):332-8. DOI: 10.1016/j. ajodo.2016.02.017.

14. Warren JJ, Bishara SE, Ortho D, Yonezu T. Tooth size-arch length relationships in the deciduous dentition: a comparison between contemporary and historical samples. Am J Orthod Dentofacials Orthop. 2003;123(6):6149. DOI: $10.1016 / 50889540603000532$.

15. Poosti M, Jalali T. Tooth size and arch dimension in uncrowded versus crowded class 1 malocclusions. J Contemp Dent Pract. 2007;8(3):45-52.

16. Carty O, Creaven V, Hennessy J, Al-Awadhi EA. A manual for space analysis in the mixed dentition. Orthod Update. 2017;8(4):118-25 DOI: $10.12968 /$ ortu.2015.8.4.118.

17. Mills LF. Arch width, arch length and tooth size in young adult males. Angle Orthod. 1964;34: 124-9.

18. Grover N, Saha S, Tripathi AM, Palit M, Dhinsa K. Applicability of Mixed Dentition Analysis in North Indian Population-A Review. Ind J Contemp Dent. 2016:4(2);1-5. DOI: 10.5958/2320-5962.2016.00024.3.

19. McKeown $M$. The diagnosis of incipient arch crowding in children. N Z Dent J. 1981;77:93-6.

20. Sardarian A, Ghaderi F. Prediction of the occurrence and severity of mandibular incisor crowding in the early mixed dentition using craniofacial parameters. Am J Orthod Dentofacial Orthop. 2018;153(5):701-7.

21. Norderval K, Wisth PJ, Boe OE. Mandibular anterior crowding in relation to tooth size and craniofacial morphology. Eur J Oral Sci. 1975; 83(5):267-73. DOI: 10.1111/j.1600-0722.1975. tb00436.x.

22. Hagberg $C$. The alignment of permanent mandibular incisors in children. A longitudinal prospective study. Eur J Orthod. 1994;16:1219.

23. Ghaderi F, Badakhsh S, Hekmatfar S. Investigation of the Relationship between the Increase in the Intercanine width and the Children's Facial Parameters; a 6-month Follow-up Study. J Dent (Shiraz). 2013;14(2):82-3.

24. Mohammad HA, Hassan MIA, Hussain SF. Dental arch dimension of Malay ethnic group. Am J Appl Sci. 2011;8(11):1061-66. 